\title{
Adaptation of material deposition parameters to account for out-time effects on prepreg tack
}

\author{
A.W. Smith ${ }^{\mathrm{a}}$, A. Endruweit ${ }^{\mathrm{b}}$, G.Y.H. Choong ${ }^{\mathrm{b}}$, D.S.A. De Focatiis ${ }^{\mathrm{b}}$, P. Hubert ${ }^{\mathrm{a}^{*}}$

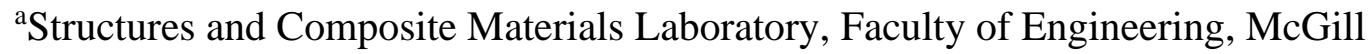 \\ University, Montreal, QC H3A 0C3, Canada \\ ${ }^{\mathrm{b} C o m p o s i t e s ~ R e s e a r c h ~ G r o u p, ~ F a c u l t y ~ o f ~ E n g i n e e r i n g, ~ U n i v e r s i t y ~ o f ~ N o t t i n g h a m, ~}$ \\ Nottingham NG7 2RD, United Kingdom \\ *Corresponding author. \\ E-mail address: pascal.hubert@mcgill.ca
}

\begin{abstract}
A single-stage peel method was employed to determine the relationship between key processing parameters and tack for a standard aerospace carbon/epoxy prepreg subjected to various levels of room-temperature out-time. The temperature-dependent viscoelasticity of the resin was studied using parallel plate rheometry and modelled using a simple Arrhenius equation. Differential scanning calorimetry and gel permeation chromatography results showed that, over a period of 35 days under ambient conditions, resin $T_{\mathrm{g}}$ increased, while no significant change in polymer chain length was observed. Time-temperature superposition was applied to construct tack master curves for each out-time interval, which were shown to approximately coincide when considering shift factors attributed to changes in $T_{\mathrm{g}}$. Process maps considering prepreg out-time were generated using tack master curves to inform process parameters and achieve desirable tack levels. This type of tailored process control is anticipated to improve resource utilization when manufacturing large preforms which take several days to complete.
\end{abstract}

Keywords: Prepreg, Adhesion, Lay-up (manual/automated), Process modeling 


\section{Introduction}

Automated lay-up manufacturing technologies such as automated fibre placement (AFP) and automated tape laying (ATL) offer improvements to part consistency and production rate when compared to hand lay-up processes $[1,2]$ where the cost of skilled manual labour represents an obstacle to the economic viability of advanced composites for certain medium-to-low volume applications. However, the occurrence of defects in prepreg lay-ups such as gaps and overlaps [3, 4], bridging [5], wrinkling [6], and spring-back [7] during material deposition can lead to interruptions in production, the need for operator intervention, and an overall increase in production times of $32 \%$ to $63 \%$ [8]. Fig. 1 shows examples of automated lay-up systems which utilize prepreg fabrics (a) and prepreg tapes (b), while also showcasing a select number of common defects (c).

To mitigate defect formation and maximize the potential of automated lay-up methods, a better understanding of the relationship between manufacturing process parameters (e.g. deposition temperature, compaction pressure, lay-up speed) and material viscoelasticity is needed. Maintaining sufficient adhesion between uncured composite layers, also known as tack, has been shown to decrease the likelihood of defect formation. Experiment-based investigations have successfully characterized tack behaviour using a variety of different approaches such as probe testing $[10,11]$ and peel testing $[12,13]$.

In industrial manufacture of composite components, prepreg can be exposed to workshop conditions (ambient temperature and humidity) for periods of several days. This material out-time affects the resin viscoelastic properties, and hence tack. Ahn et al. [14], Endruweit et al. [15], and Budelmann et al. [16] have quantified the effect of prepreg outtime on tack. 
The aim of this work is to enable the prediction of the evolution of prepreg tack with material out-time, thus informing deposition parameters to achieve peak tack. The single-stage peel method proposed by Crossley et al. [17] is used to determine the relationship between deposition temperature, deposition rate, and tack for a standard aerospace carbon/epoxy prepreg subjected to room-temperature ageing. This data is correlated to calorimetric measurements employed in a curing model for the evolution of resin glass transition temperature and allows the determination of peak tack conditions to be described as a function of material out-time.

(a)

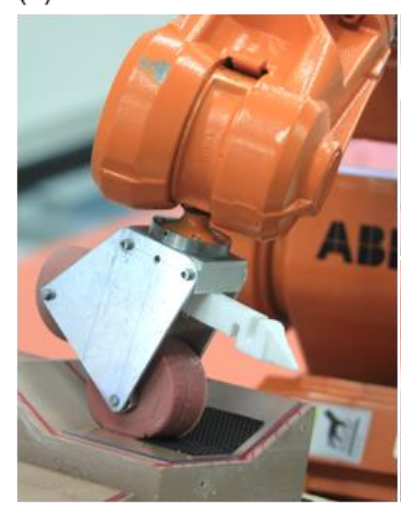

(c1)

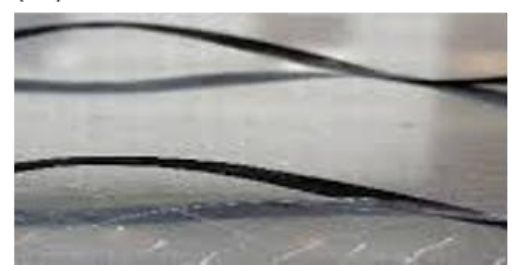

(b)

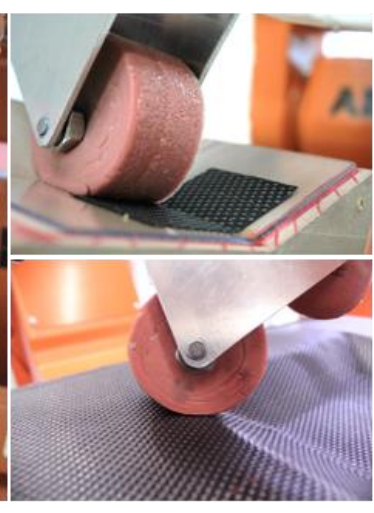

(c2)

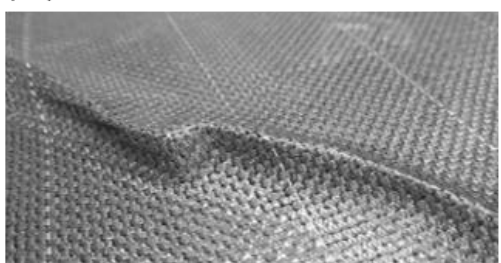

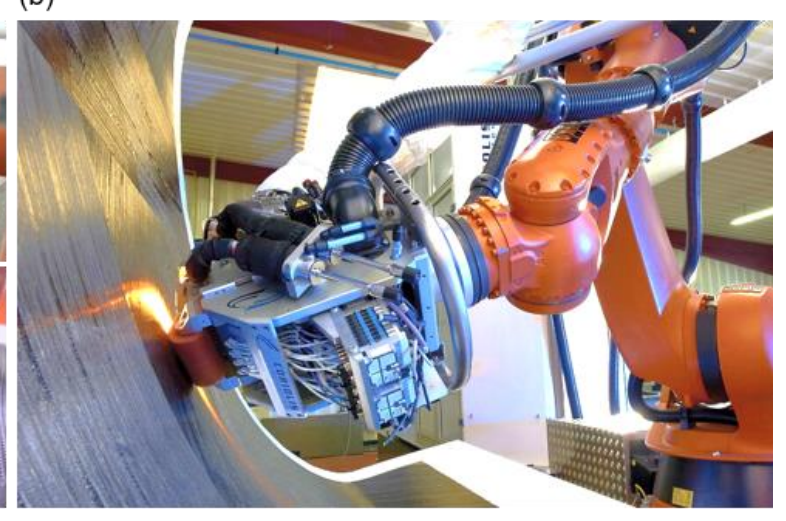

(c3)

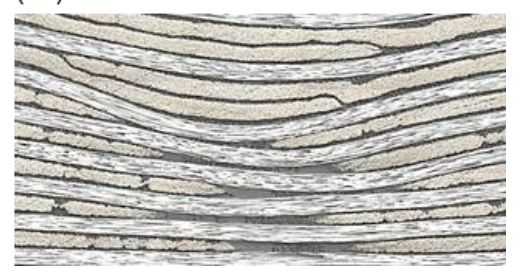

Fig. 1. Automated prepreg fabric lay-up (a) and automated fibre placement (b) systems [2]; some typical manufacturing defects associated with automated lay-up: non-adhering tapes (c1) [9], ply wrinkling (c2), and gaps and overlaps after curing (c3) [4]. 


\section{Material}

A commercially available aerospace grade prepreg system manufactured by Cytec Engineered Materials Inc. was used for all the tack testing shown here. The system consists of a Thornel T650 - PAN carbon fibre reinforcement and Cytec's Cycom ${ }^{\circledR}$ 5276-1 toughened epoxy [18]. The prepreg architecture is a standard 3k-tow plain weave with an approximate resin content of $36 \%$ by weight. The material is referred to as PW/5276-1 from this point onward. For complementary calorimetry experiments, additional prepreg in the form of an eight-harness satin (8HS) variant of this material was used.

\section{Experimental methods}

\subsection{Tack testing}

Prepreg tack was measured employing the continuous application-and-peel method discussed in detail by Crossley et al. [19]. A rectangular prepreg specimen is laid up by hand on a rectangular substrate (dimensions $140 \mathrm{~mm} \times 80 \mathrm{~mm}$ ) such that one end of the specimen is flush with the edge of the substrate. Substrate and specimen are then loaded into a test fixture, where a stiff compaction roller presses the prepreg against the substrate and against a stiff peel roller at a controlled force. The fixture is mounted on the base of a universal testing machine. The free end of the prepreg specimen is attached to the crosshead and load cell of the testing machine through a material clamp, such that the horizontally orientated specimen is bent around the peel roller. In a tack test, the cross-head moves vertically at a set speed, which translates into horizontal movement of specimen and substrate through the fixture. As a result, the prepreg is bonded to and peeled from the substrate in a single continuous motion at a "feed rate", or "peel rate", which corresponds 
to the cross-head speed. Here, the duration of compaction is inversely proportional to the feed rate.

In this study, the test procedure described above was employed to measure tack between plies of PW/5276-1 and a polished steel substrate. All tests were carried out at a specimen width of $75 \mathrm{~mm}$ and at a compaction force of $100 \mathrm{~N}$. The total length of contact between the prepreg and the substrate was $80 \mathrm{~mm}$. By incorporating an environmental chamber into the test setup, the test temperature, $T$, was varied $\left(18^{\circ} \mathrm{C}, 28{ }^{\circ} \mathrm{C}, 38^{\circ} \mathrm{C}, 50^{\circ} \mathrm{C}\right)$, as well as the test feed rate, $r\left(25 \mathrm{~mm} \mathrm{~min}^{-1}, 70 \mathrm{~mm} \mathrm{~min}^{-1}, 180 \mathrm{~mm} \mathrm{~min}^{-1}, 500 \mathrm{~mm} \mathrm{~min}^{-1}\right)$. The measured tensile force as a function of cross-head displacement for a representative tack test is shown in Fig. 2(a). In this figure, two phases of the continuous test can be distinguished. In the first phase, a protective film, which partially covers the prepreg surface, prevents adhesion from forming between prepreg and substrate. Only the force needed to overcome the dissipative effects arising from friction and bending the prepreg ply, $F_{\text {diss, }}$ is measured in this phase. In the second phase of the test, where the exposed part of the prepreg surface is in contact with the substrate, the measured force, $F_{\text {peel }}$, corresponds to the sum of $F_{\text {diss }}$ and the tack force, $F_{\mathrm{t}}$. Hence, the tack force is quantified as the difference between $F_{\text {peel }}$ and $F_{\text {diss }}$ [19]. It is independent of the magnitude of dissipative effects.

In previous work, it was found that, under specific temperature and peel rate conditions, measured tack increases continuously with increasing compaction force and converges to a limit value [15]. Tack measured using a compliant peel roller (coated in polyurethane) was also observed to be typically higher than that measured using a stiff peel 
roller of the same diameter at the same compaction force. However, the general trend and the limit tack value were not affected by the roller type. For all tests reported here, the compaction force was $100 \mathrm{~N}$ at a specimen width of $75 \mathrm{~mm}$, and a stiff peel roller was used. A single specimen was tested for each combination of out-time, temperature and peel rate. Local variations in peel force and dissipative effects are averaged in each test, as the forces are recorded for a finite length (and across a given width) of the specimens (Fig. 2(a)).

\subsection{Prepreg surface morphology}

In both the dissipative regime and the ply peel regime of the PW/5276-1 tack trials, large oscillations were observed, which were not present in previous tack tests on uni-directional prepregs [15]. As this periodic behaviour is observed in the dissipative regime, where prepreg and substrate are separated by a backing film, it cannot be related to the tack phenomenon. In several cases, the period of the oscillation, $\Delta d$, was found to closely match the plain-weave tow spacing, $\Delta d^{\prime}$, shown in Figs. 2(a) and (b). This indicates that some component of the observed tack variability is caused by the periodic thickness variations in the woven fabric. However, a definitive measure of tack variability would not be possible without further investigation and so no conclusive definition of tack variability is discussed here and only the average tack force values are reported.

Having observed the potential effect of prepreg surface morphology on tack measurement, tests were also performed on either side of the PW/5276-1 prepreg to assess any differences. Because the plain-weave studied here features in-plane geometric symmetry, one would not expect there to be a significant difference. However, Endruweit et al. [15] showed that, as a result of the method of prepreg manufacture, the presence of 
backing film can yield significantly different resin distributions on both faces. For an arbitrary set of test conditions ( $t_{\text {out }}=0$ days, $\left.T=28^{\circ} \mathrm{C}, r=180 \mathrm{~mm} \mathrm{~min}^{-1}\right)$, tack was measured on both prepreg faces. Observed average values, $6.72 \mathrm{~N}$ and $6.30 \mathrm{~N}$, respectively, indicate that, for the prepreg characterised in this work, there is no significant difference in tack between both faces of the prepreg. Nevertheless, all subsequent tests were performed on the same prepreg surface in contact with the steel substrate.
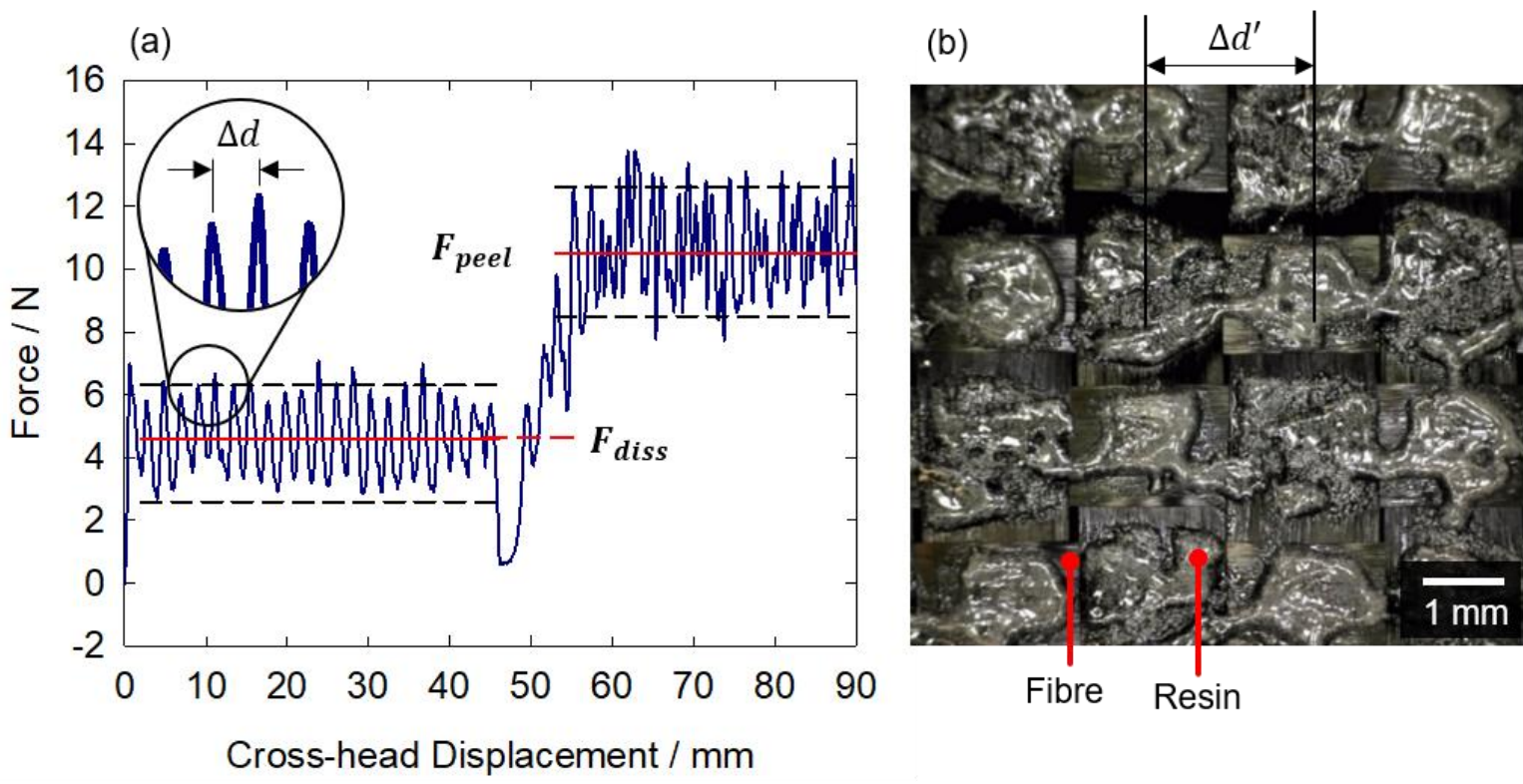

Fig. 2. Measured tensile force as a function of the cross-head displacement during a representative (a) tack test showing the period of signal variation, $\Delta d$, and the (b) plain-weave tow spacing, $\Delta d^{\prime}$.

\subsection{Specimen preparation}

From prepreg sheets, specimens were cut to the required dimensions $(215 \mathrm{~mm} \times 75$ $\mathrm{mm}$ ) for tack testing. All specimens were cut such that the long edge was parallel to the fabric warp direction. Different batches of specimens were then exposed to laboratory conditions (temperature and humidity) for periods of 7 days, 14 days, 21 days or 35 days. 
Each specimen was stored with polymeric film covering both faces to prevent adhesion from taking place between specimens. The temperature, $T$, and relative humidity, $R H$, were recorded throughout the material out-time (Table 1) using a Lascar EL-GFX-2 logger.

Table 1. Temperature, $T$, and relative humidity, $R H$, recorded during different out-times, $t_{\text {out }}$; average values, standard deviations, and minima and maxima are given.

\begin{tabular}{|c|cc|cc|cc|cc|}
\hline \multirow{2}{*}{$t_{\text {out }}=7$ days } & \multicolumn{2}{|c|}{$t_{\text {out }}=14$ days } & \multicolumn{2}{c|}{$t_{\text {out }}=21$ days } & \multicolumn{2}{c|}{$t_{\text {out }}=35$ days } \\
& $T /{ }^{\circ} \mathrm{C}$ & $R H / \%$ & $T /{ }^{\circ} \mathrm{C}$ & $R H / \%$ & $T /{ }^{\circ} \mathrm{C}$ & $R H / \%$ & $T /{ }^{\circ} \mathrm{C}$ & $R H / \%$ \\
\hline average & 17.7 & 45.7 & 17.6 & 43.9 & 17.7 & 44.2 & 17.7 & 42.8 \\
st.dev. & 1.1 & 2.6 & 1.0 & 2.7 & 1.0 & 2.4 & 0.9 & 3.3 \\
$\min$ & 13.0 & 42.7 & 13.0 & 40.2 & 13.0 & 40.2 & 13.0 & 36.1 \\
$\max$ & 19.3 & 56.3 & 19.3 & 56.3 & 19.3 & 56.3 & 19.3 & 56.3 \\
\hline
\end{tabular}

\subsection{Differential scanning calorimetry}

The glass transition temperature, $T_{\mathrm{g}}$, of the epoxy resin system at different out-times was determined using Modulated Differential Scanning Calorimetry (MDSC). Three different prepreg batches were aged for these experiments: A batch of PW/5276-1 was stored together with the tack specimens under the conditions outlined in Table 1, and characterised using a TA Instruments DSC 2500. Separate batches of PW/5276-1 and $8 \mathrm{HS} / 5276-1$ were exposed to an average temperature of $21^{\circ} \mathrm{C}$ for intervals up to 400 days and characterised using a TA Instruments DSC Q1000. In all cases, MDSC tests consisted of a $2{ }^{\circ} \mathrm{C} \mathrm{min}-1$ ramp from $-50{ }^{\circ} \mathrm{C}$ to $80{ }^{\circ} \mathrm{C}$ with a temperature modulation of $\pm 1.27{ }^{\circ} \mathrm{C}$ every $60 \mathrm{~s}$. A minimum of three repetitions were performed for each ageing condition using hermetically sealed aluminium pans. MDSC was also used to explore the relationship between degree-of-cure and $T_{g}$ for 5276-1. Neat resin (NR) and prepreg specimens were 
processed under a series of different time-temperature conditions to obtain incremental levels of cure from $0 \%$ to $100 \%$. A summary of the $T_{\mathrm{g}}$ tests performed is shown below in Table 2.

Table 2. MDSC test matrix for 5276-1 glass transition temperature characterization.

\begin{tabular}{ccc}
\hline Test Type & Form & Test Conditions \\
\hline Dynamic Ramp & $\mathrm{NR}, 8 \mathrm{HS}$ & $2{ }^{\circ} \mathrm{C} \mathrm{min}^{-1}$ \\
Isothermal Dwell & $\mathrm{NR}$ & $80,100,120,140,160^{\circ} \mathrm{C}$ \\
Sequential Ramp & $\mathrm{PW}$ & $150,155,160,175,275^{\circ} \mathrm{C}$ \\
& & $5-60 \mathrm{~min}(\Delta t=5 \mathrm{~min})$ \\
Interrupted Isotherm & $\mathrm{NR}, 8 \mathrm{HS}$ & $32,87,107,122,130.5 \mathrm{~min}$ \\
\hline
\end{tabular}

\subsection{Gel permeation chromatography}

Gel permeation chromatography (GPC) was carried out to determine the potential change in resin molecular mass due to polymerization. For each ageing condition, resin solutions were prepared in dimethylformamide (DMF) at a concentration of $\sim 2 \mathrm{mg} \mathrm{ml}^{-1}$. GPC measurements were performed in $\mathrm{DMF}+0.1 \%$ lithium bromide eluent relative to poly(methyl methacrylate) standards at $50{ }^{\circ} \mathrm{C}$, using a PL50 Polymer Laboratories system employing two mixed bed (D) columns equipped with a refractive index detector.

\subsection{Rheometry}

Isothermal frequency sweeps were performed using an Anton Paar MCR 302 rheometer (plate-plate configuration) fitted with a CTD 450 environmental chamber and a Grant Instruments LTD6 refrigerated circulator for controlled heating and cooling, 
respectively. Since 5276-1 neat resin specimens were not available for these tests, frequency sweeps were performed directly on prepreg specimens cut to a size of $30 \mathrm{~mm} \times$ $30 \mathrm{~mm}$. Although the magnitude of the viscoelastic measurements is strongly affected by the presence and distribution of the fibres in the material, observed changes in the storage modulus $G^{\prime}$ with temperature can be attributed to the resin system alone, since the fibres do not exhibit any significant temperature dependent behaviour for the range examined in this work.

All tests were carried out using a standard $25 \mathrm{~mm}$ diameter parallel plate geometry in an air atmosphere. At the beginning of each test, the specimen is subjected to a normal force of $20 \mathrm{~N}$ at the lowest test temperature. This step promotes contact between the rheometer plates and the specimen prior to fixing the gap distance. Isothermal frequency sweeps are then carried out between $15^{\circ} \mathrm{C}$ and $60^{\circ} \mathrm{C}$ (in increments of $5^{\circ} \mathrm{C}$ ) at logarithmically increasing frequencies $f$ from $1 \mathrm{~Hz}$ to $10 \mathrm{~Hz}$, and at a fixed strain amplitude of $0.01 \%$. The amplitude was kept small in order to avoid disrupting the fibre arrangements. It is to be noted that the range of test temperatures for $t_{\mathrm{out}}=35$ days was limited to $25^{\circ} \mathrm{C}$ to $60{ }^{\circ} \mathrm{C}$ due to an increase in $T_{\mathrm{g}}$. 


\section{Results}

\subsection{Frequency sweeps and horizontal shifting}

Fig. 3 illustrates a typical frequency sweep, as described above, on a prepreg specimen aged to $t_{\mathrm{out}}=7$ days. All out-times investigated exhibited the same general trend of the moduli with respect to frequency. Maximum temperatures were limited to $60{ }^{\circ} \mathrm{C}$ to avoid significant cure advancement during the measurements. The limited frequency range and relatively high frequency values were selected to reduce test duration and ensure that the resin degree of cure remained unchanged, particularly at elevated temperatures. The high moduli of $>10^{5} \mathrm{~Pa}$ in the low frequency region (i.e. the high temperature measurements), where a neat resin system is expected to flow, are attributed to the presence of the fibres. 


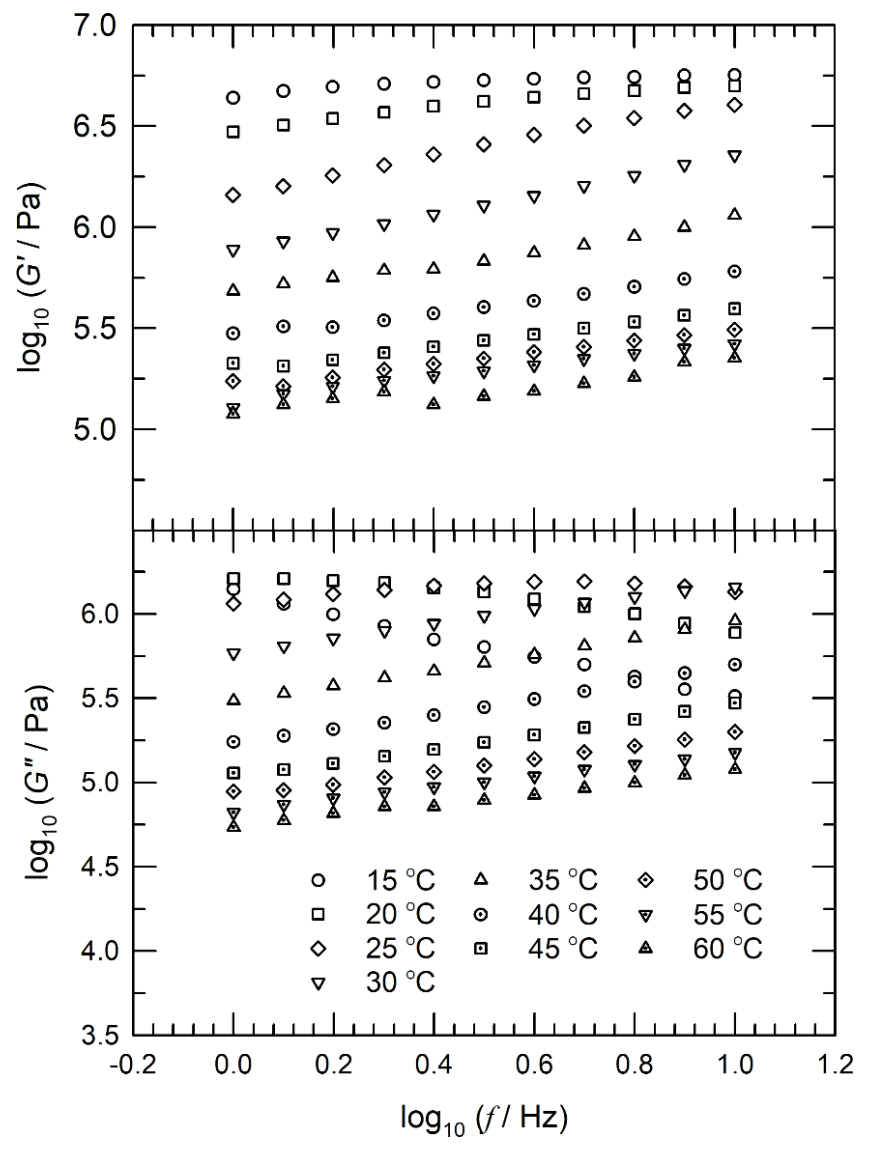

Fig. 3. Example of frequency sweeps of (a) storage modulus $G$ ' and (b) loss modulus $G$ ” of aged prepreg with $t_{\text {out }}=7$ days measured at temperatures $15^{\circ} \mathrm{C}$ to $60^{\circ} \mathrm{C}$ at a strain amplitude of $0.01 \%$.

Employing the principle of time-temperature equivalence, the rheological measurements shown in Fig. 3 were shifted along the frequency axis to an arbitrary reference temperature $T_{\text {ref }}=25{ }^{\circ} \mathrm{C}$ to produce a master curve illustrated in Fig. 4. Horizontal shift factors, $a$, were obtained using an automated procedure [20] which seeks to minimize the area enclosed by adjacent data sets. It was found that the data obtained from different temperatures satisfactorily shift to yield the respective master curves for all out-times and for as received prepreg. This confirms that the rheometry carried out provides insight into 
the resin time-temperature dependence. Fig. 5 shows that the shift factors as a function of test temperature for each prepreg out-time investigated are very similar.

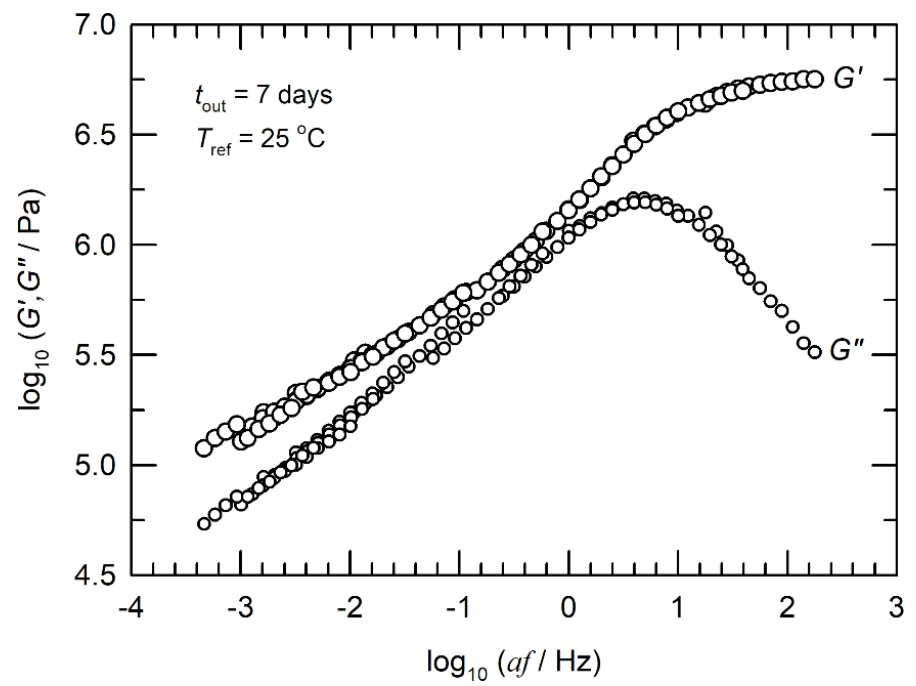

Fig. 4. Rheological master curve of prepreg with $t_{\text {out }}=7$ days at $T_{\text {ref }}=25^{\circ} \mathrm{C}$.

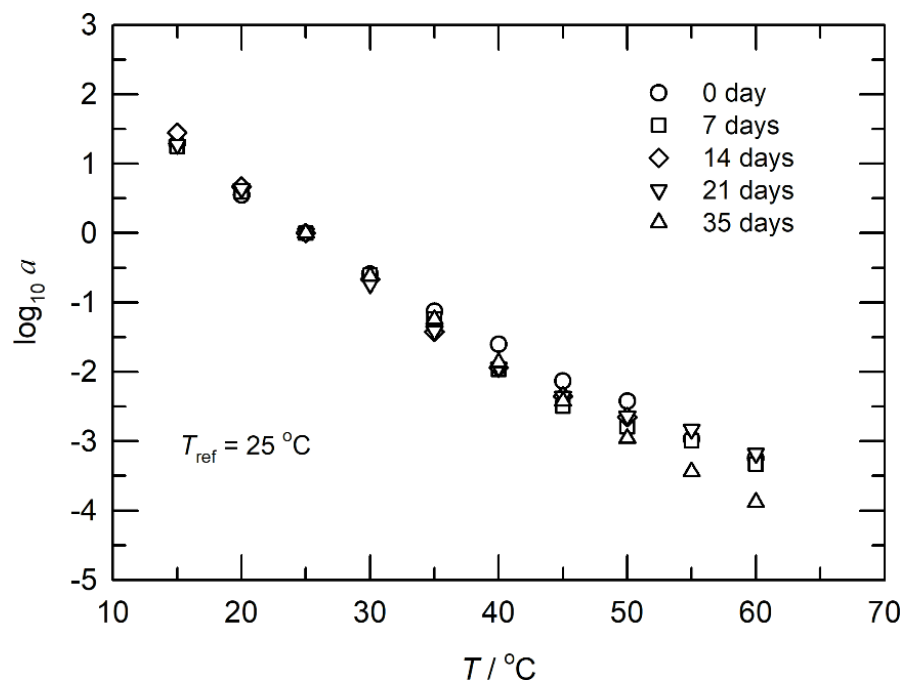

Fig. 5. Horizontal shift factors, $a$ employed to obtain master curves of as-received and aged prepreg at $t_{\text {out }}=7,14,21$ and 35 days at $T_{\text {ref }}=25^{\circ} \mathrm{C}$. 
Since both chemical and physical changes can have a significant influence on the resin behaviour, GPC was performed on resin extracted from the prepreg specimens at the various out-times to monitor for structural modifications such as chemical cross-linking. Measurements of the number-average, $M_{\mathrm{n}}$, and weight-average, $M_{\mathrm{w}}$, of the molar mass distribution of the epoxy resin at different out-times are reported in Table 3. The GPC results indicate that increasing out-time had no significant effect on the molar mass distribution, and hence on the length of resin polymer chains.

Table 3. Measurements of molar mass determined from GPC of 5276-1 specimens.

\begin{tabular}{ccc}
\hline$t_{\text {out }} /$ days & $M_{\mathrm{n}} / \mathrm{kg} \mathrm{mol}^{-1}$ & $M_{\mathrm{w}} / \mathrm{kg} \mathrm{mol}^{-1}$ \\
\hline 0 & 42.4 & 58.6 \\
7 & 37.6 & 55.7 \\
14 & 38.4 & 56.6 \\
21 & 38.6 & 56.8 \\
35 & 41.9 & 58.9 \\
\hline
\end{tabular}

Having demonstrated that the out-time does not lead to any measurable change in the molecular weight ditribution of this resin, it is suggested that observable changes in prepreg behaviour with out-time could be attributed to changes in $T_{\mathrm{g}}$, reported in Table 4 .

Table 4. Glass transition temperature, $T_{\mathrm{g}}$, as a function of out-time, $t_{\mathrm{out}}$.

\begin{tabular}{cc}
\hline$t_{\text {out }} /$ days & $T_{\mathrm{g}} /{ }^{\circ} \mathrm{C}$ \\
\hline 0 & $-0.2 \pm 0.8$ \\
7 & $4.0 \pm 0.4$ \\
14 & $6.4 \pm 0.4$ \\
21 & $8.3 \pm 0.8$ \\
35 & $16.8 \pm 0.7$ \\
\hline
\end{tabular}


In order to account for both temperature and glass transition changes, a temperature shift factor $a_{T}$ and a shift factor that relates to the shift of $T_{\mathrm{g}}, a_{T \mathrm{~g}}$, are defined as follows:

$$
\begin{gathered}
\log _{10} a_{T}=\frac{E}{R}\left(\frac{1}{T}-\frac{1}{T_{\text {ref }}}\right), \\
\log _{10} a_{T_{g}}=\frac{E}{R}\left(\frac{1}{T_{\mathrm{g}, 0}}-\frac{1}{T_{\mathrm{g}}}\right),
\end{gathered}
$$

where $R$ is the universal gas constant $\left(8.31 \mathrm{~J} \mathrm{~K}^{-1} \mathrm{~mol}^{-1}\right), E$ is an activation energy, $T$ and $T_{\text {ref }}$ are the test and reference temperatures and $T_{\mathrm{g}, 0}$ is the glass transition temperature at 0 day out-time, all expressed in Kelvin. As defined here, $a_{T}$ allows rates to be shifted from a measurement temperature $T$ to a reference temperature $T_{\text {ref, }}$, whereas $a_{T \mathrm{~g}}$ represents the shift from a virgin condition defined by $T_{\mathrm{g}, 0}$ to an aged condition defined by $T_{\mathrm{g}}$. By arbitrarily letting $T_{\text {ref }}=T_{\mathrm{g}, 0}$, it is possible to plot a single master curve from all the data since the combined shift factor for all out-times becomes:

$$
\log _{10} a_{T} a_{T_{g}}=\frac{E}{R}\left(\frac{1}{T}-\frac{1}{T_{\mathrm{g}}}\right),
$$

where $E$ can be obtained from the Arrhenius plot in Fig. 6. Since shift factors were not measured directly at $T_{\mathrm{g}}$, they were calculated from individual Arrhenius plots for each out-time. Across the time and temperature ranges explored here, relaxation processes occurring in the resin are therefore only a function of the proximity of $T$ to $T_{\mathrm{g}}$. Fig. 6 shows that the observed shifts in prepregs with and without out-time can be accounted for through the additional shift factor $a_{T \mathrm{~g}}$. Linear regression through the data yielded $E=(81 \pm 2) \mathrm{kJ}$ $\mathrm{mol}^{-1}$ with a coefficient of determination $R^{2}=0.99$. As $E$ is affected by several processes, such as polymer relaxation and partial curing induced by elevated temperatures, it is 
essentially employed as a parameter representing the observed temperature dependence as opposed to a chemical or physical activation energy.

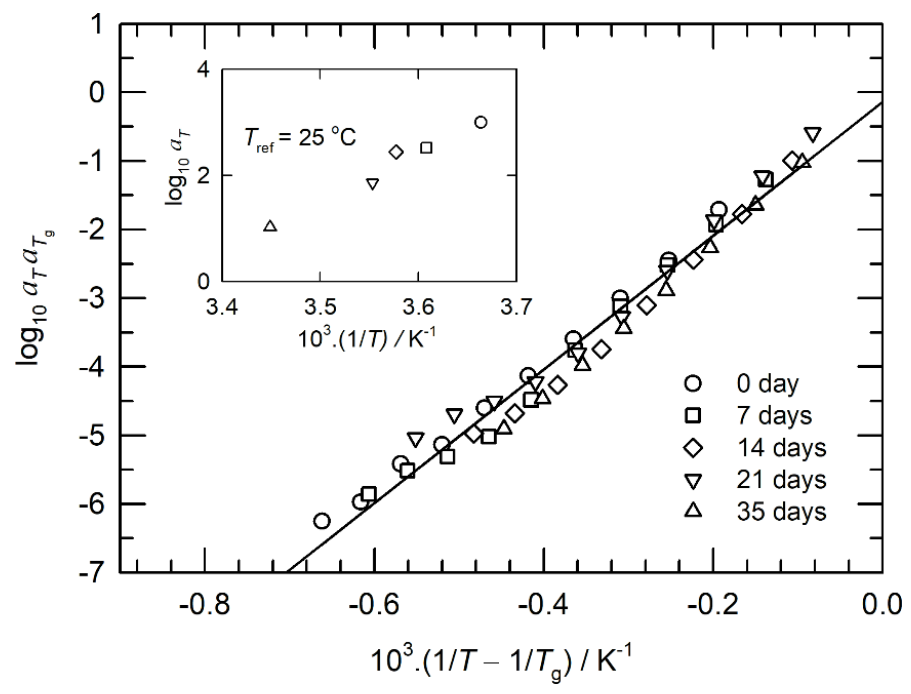

Fig. 6. Arrhenius plot for prepregs without out-time and with $t_{\text {out }}=7,14,21$, and 35 days at $T_{\text {ref }}=T_{\mathrm{g}, 0}$ determined using Eq. (1). Inset shows the shift factors between $T_{\text {ref }}=25^{\circ} \mathrm{C}$ and the $T_{\mathrm{g}}$ for each $t_{\text {out }}$.

\section{2 $T_{\mathrm{g}}$ model}

The DiBenedetto equation [21] was chosen to model the relationship between $T_{\mathrm{g}}$ values obtained through the experiments described in Table 2 and the degree of cure:

$$
\frac{T_{\mathrm{g}}-T_{\mathrm{g} 0}}{T_{\mathrm{g} \infty}-T_{\mathrm{g} 0}}=\frac{\lambda \alpha}{1-(1-\lambda) \alpha} .
$$

In Eq. (4), $T_{\mathrm{g}, 0}, T_{\mathrm{g}, \infty}$, and $T_{\mathrm{g}}$ are the initial $(\alpha=0)$, final $(\alpha=1)$, and intermediate

$(0<\alpha<1)$ glass transition temperatures respectively. $\lambda$ is a fitting parameter defined by Pascault and Williams [22] as "the ratio of segmental mobilities for a certain extent of reaction $[\alpha]$ with respect to the mixture of monomers $[\alpha=0]$ '. This parameter is said to vary between 0 and 1 based on the experimental investigations of Adabbo and Williams 
[23] and Enns and Gillham [24]. Using a weighted non-linear least-squares regression, a value of $\lambda=0.61$ was found to give the best model fit with an adjusted coefficient of determination of $R^{2}=0.99$. Both experimental data and model predictions are shown in Fig. 7.

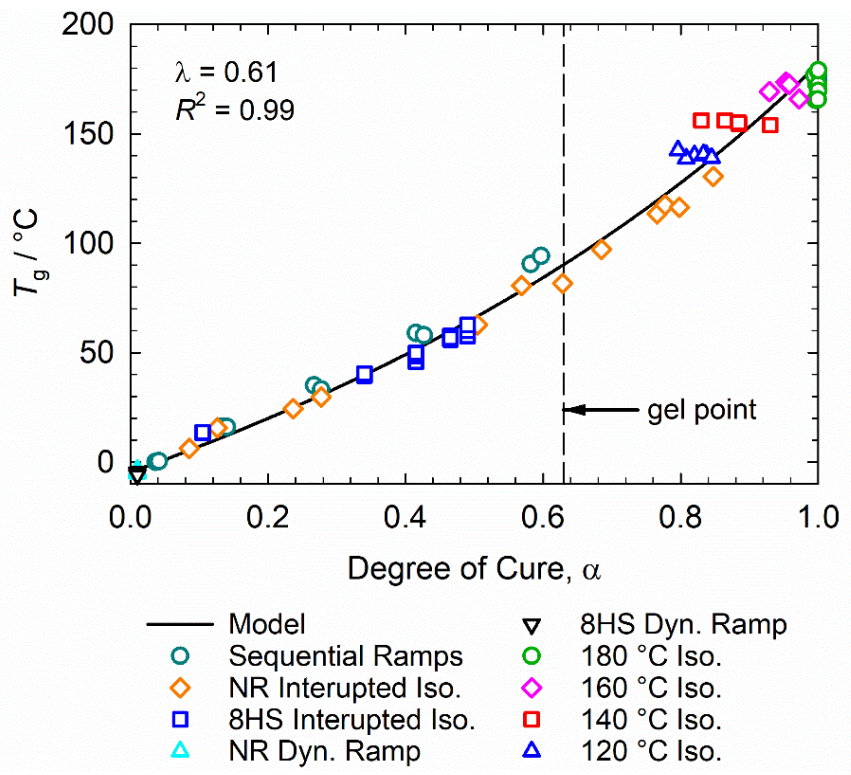

Fig. 7. Measured and predicted glass transition temperatures for 5276-1 at various degrees of cure.

\subsection{Room-temperature cure model}

The ability to predict changes in resin state is needed if the evolution of tack with out-time is to be accounted for in prepreg processing. The DSC and GPC results presented above have shown that $T_{\mathrm{g}}$ increases significantly over a period of 35 days, while the resin molar mass remains largely unchanged. Having described the relationship between $T_{\mathrm{g}}$ and degree of cure using the DiBenedetto equation, the DSC measurements outlined in Section 3.4 were used to produce cure rate evolution data. A single-term autocatalytic cure model 
with diffusion (Eq. (5)) was then selected for fitting using the recommendations outlined by Dykeman [25].

$$
\frac{d \alpha}{d t}=\frac{K \alpha^{m}(1-\alpha)^{n}}{1+\exp \left(D\left(\alpha-\left(\alpha_{\mathrm{C} 0}+\alpha_{\mathrm{CT}} T\right)\right)\right)}
$$

Here, $m$ and $n$ are reaction orders, $D$ is the diffusion coefficient, $\alpha_{C O}$ is the critical degree of cure at absolute zero, $\alpha_{C T}$ is the rate of increase of critical degree of cure with temperature, and $T$ is temperature in units of Kelvin. The Arrhenius coefficient, $K$, is defined as:

$$
K=A \exp \left(\frac{-E_{\mathrm{a}}}{R T}\right)
$$

where $A$ is the pre-exponential factor and $E_{\mathrm{a}}$ is the resin activation enthalpy.

Ideal cure model parameters were obtained through a non-linear least-squares regression and are shown in Table 5. The room-temperature cure model predictions are compared with the experimental data in Fig. 8.

Table 5. Room-temperature cure model parameters for 5276-1.

\begin{tabular}{cc}
\hline Parameter & Value \\
\hline$A$ & $7.02 \times 10^{4} \mathrm{~s}^{-1}$ \\
$E_{\mathrm{a}}$ & $61.4 \mathrm{~kJ} \mathrm{~mol}^{-1}$ \\
$m$ & 0.94 \\
$n$ & 0.00 \\
$\alpha_{\mathrm{C} 0}$ & $-1.48 \times 10^{-1}$ \\
$\alpha_{\mathrm{CT}}$ & $1.00 \times 10^{-3}$ \\
$D$ & 18.6 \\
\hline
\end{tabular}

Practically speaking, it may not be feasible for an original equipment manufacturer to perform a study with a scope large enough to populate a room-temperature cure model. 
By limiting the out-time to within the manufacturer-specified out-life, Fig. 9 demonstrates that a simple linear regression can be used to approximate changes in $T_{\mathrm{g}}$.
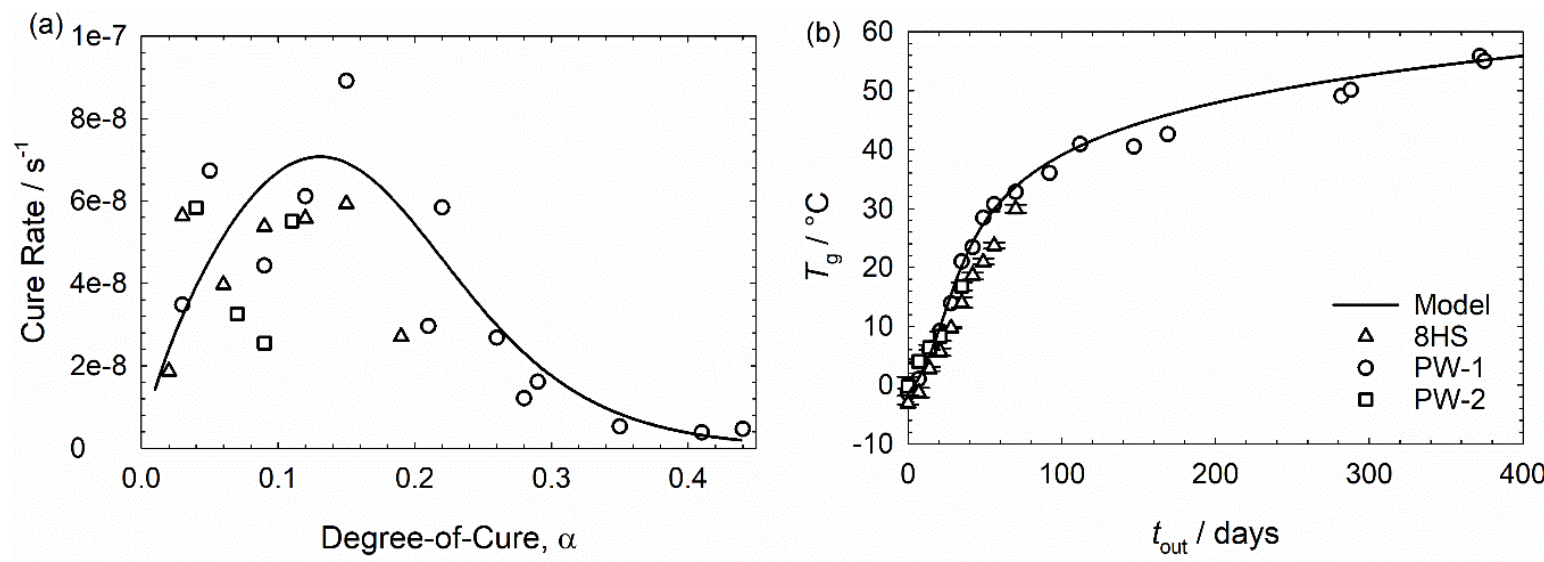

Fig. 8. Measured cure rate versus degree of cure (a) and $T_{g}$ evolution versus out-time data (b) showing the room-temperature model predictions.

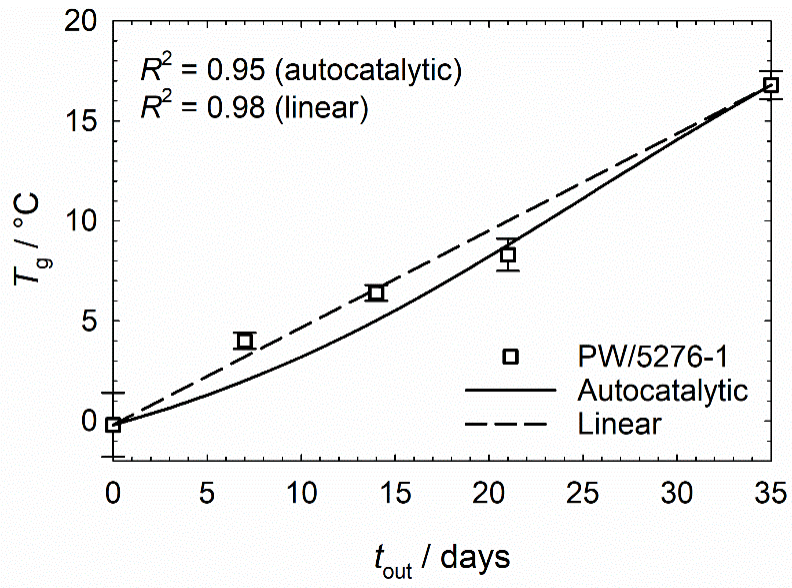

Fig. 9. $T_{g}$ evolution data shown within a time-frame representative of the material out-life. Room-temperature cure model and linear regression shown with corresponding coefficients of determination. 


\section{Discussion}

\subsection{Time-temperature superposition}

As shown by Crossley et al. [19], the principle of time-temperature superposition is applicable to tack data acquired in continuous application-and-peel tests. This implies that the tack force, $F_{\mathrm{t}}$, measured at temperature, $T$, and feed rate, $r$, is equivalent to the tack force at a reference temperature, $T_{\mathrm{ref}}$, and at a shifted feed rate, $a_{T}$ :

$$
F_{\mathrm{t}}(T, r)=F_{\mathrm{t}}\left(T_{\text {ref }}, a_{\mathrm{T}} r\right)
$$

In previous work [14], the shift factor, $a_{T}$, was determined from complementary rheological experiments. The dependence of $a_{T}$ on temperature at $T_{\text {ref }}$ was described by the Williams, Landel and Ferry (WLF) equation [26]. It was shown that tack master curves generated using WLF shift factors can be approximated by Gaussian curves described by:

$$
F_{\mathrm{t}}\left(T_{\text {ref }}, a_{T} r\right)=F_{\mathrm{t}, \text { max }} \exp \left(-\left(\frac{\log \left(a_{T} r\right)-\log \left(r_{\text {max }, T_{\text {ref }}}\right)}{w}\right)^{2}\right)
$$

Here, $F_{\mathrm{t}, \max }$ is the maximum tack force, $a_{T} r$ is the shifted feed rate, $r_{\max , T r e f}$ is the rate at maximum tack at the reference temperature $T_{\text {ref, }}$ and $w$ indicates the width of the curve. The shape of the master curves is specific to the continuous application-and-peel test method. It reflects the competing effects of increasing cohesion within the resin and decreasing adhesion between resin and substrate with increasing feed rates. Maximum tack and feed rate at the maximum derived from fitted Gaussian curves can be used to quantitatively describe tack behaviour at any reference temperature.

For the resin system studied here, as shown in Section 4.1 (Fig. 6), the Arrhenius equation was found to be sufficient for the description of the dependence of the shift factor on temperature. Therefore, there is no need to determine two empirical constants as used in 
the WLF equation. The applicability of the Arrhenius equation to the resin data can be explained by the relatively close proximity of the rheometry temperatures to the $T_{\mathrm{g}}$ of the resin at different levels of out-time.

\subsection{Tack master curves}

Applying Eq. (1) to shift tack data obtained for each out-time to a reference temperature $T_{\text {ref }}=25^{\circ} \mathrm{C}$ gives the tack master curves plotted in Fig.10. Fitting of Gaussian curves (Eq. (7)) allows $F_{\mathrm{t}, \max }$ and $r_{\max }$ to be determined as quantitative descriptors of tack at $T_{\text {ref }}=25{ }^{\circ} \mathrm{C}$ (Table 6). With increasing out-time, the shifted feed rate at maximum tack decreases consistently, while a small decrease in $F_{\mathrm{t}, \mathrm{max}}$ is observed. These observations are consistent with results for a unidirectional carbon fibre/epoxy resin prepreg presented elsewhere [15].

Shifting the tack data for each ageing condition to the corresponding $T_{\mathrm{g}}$, Eq. (1) gives the curves plotted in Fig. 11. This approach results in the master curves for all outtimes to approximately coincide, which is reflected in similar values of $a_{T} a_{T \mathrm{~g}} r_{\max }$ (Table 6). This indicates that changes in $T_{\mathrm{g}}$ due to out-time are primarily responsible for the observed changes in resin relaxation timescales. This result demonstrates that the cure state is a crucial component in determining the polymer time-temperature dependence behaviour and that $T_{\mathrm{g}}$ is an appropriate indicator of low degrees of cure. The use of a shift factor to address structural changes in the prepreg is similar to that proposed by Derail et al. [27] to address changes in molecular weight in the peeling of adhesives. 
Furthermore, the good overlap observed in the rheological master curve implies that rheometry using prepreg to obtain the time-temperature dependence is feasible when neat resin is not available, although direct measurement of resin rheology is preferable. 


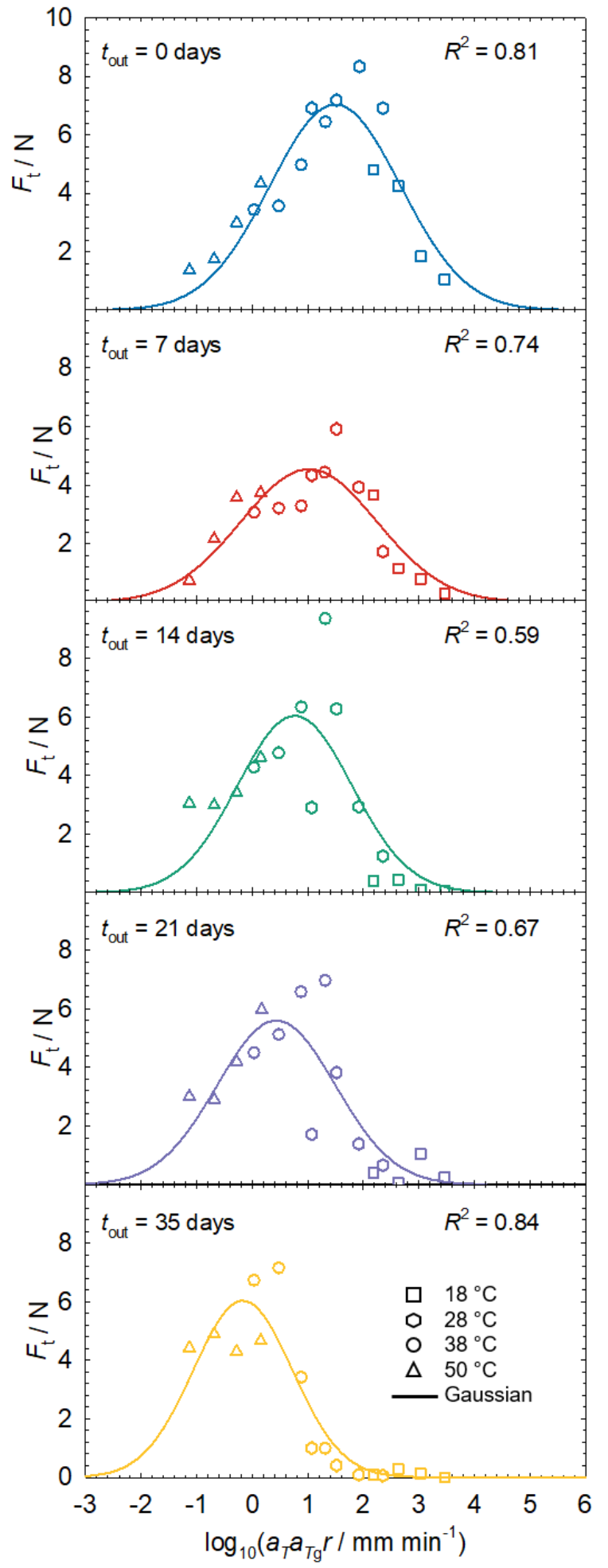

Fig. 10. Tack data at different out-times, test temperatures and feed rates, shifted using a reference temperature and glass transition temperature of $T_{\text {ref }}=25^{\circ} \mathrm{C}$ and $T_{\mathrm{g}}=T_{\mathrm{g}, 0}$ respectively. Tack force is shown as a function of the shifted feed rate. The solid lines indicate Gaussian regressions according to

Eq. (8) with corresponding coefficients of determination shown. 
Table 6. Maximum tack force, $F_{\mathrm{t}, \mathrm{max}}$, and shifted feed rate at maximum tack, $a_{\mathrm{T}} r_{\max }\left(T_{\mathrm{ref}}=25^{\circ} \mathrm{C}\right)$ are derived from Gaussian fit curves according to Eq. (8). The feed rate at maximum tack for all out-times were shifted to $T_{\mathrm{g}}=T_{\mathrm{g}, 0}$ (i.e. $t_{\mathrm{out}}=0$ day) using $a_{\mathrm{T}} a_{\mathrm{Tg}} r_{\max }$ to account for the out-time effects on $T_{\mathrm{g}}$. Average values and standard errors are given.

\begin{tabular}{cccc}
\hline \multicolumn{1}{c}{$t_{\text {out }} /$ days } & $F_{\mathrm{t}, \max } / \mathrm{N}$ & $a_{T} r_{\max } /\left(\mathrm{mm} \mathrm{min}^{-1}\right)$ & $a_{T} a_{T \mathrm{~g}} r_{\max } /\left(\mathrm{mm} \mathrm{min}^{-1}\right)$ \\
\hline 0 & $7.03 \pm 0.47$ & $31.67 \pm 7.03$ & $31.67 \pm 7.03$ \\
7 & $4.55 \pm 0.37$ & $10.64 \pm 2.96$ & $37.01 \pm 10.29$ \\
14 & $6.03 \pm 0.84$ & $5.92 \pm 2.36$ & $41.31 \pm 16.44$ \\
21 & $5.60 \pm 0.68$ & $2.74 \pm 1.05$ & $32.86 \pm 12.58$ \\
35 & $6.05 \pm 0.57$ & $0.68 \pm 0.20$ & $84.58 \pm 24.29$ \\
\hline
\end{tabular}
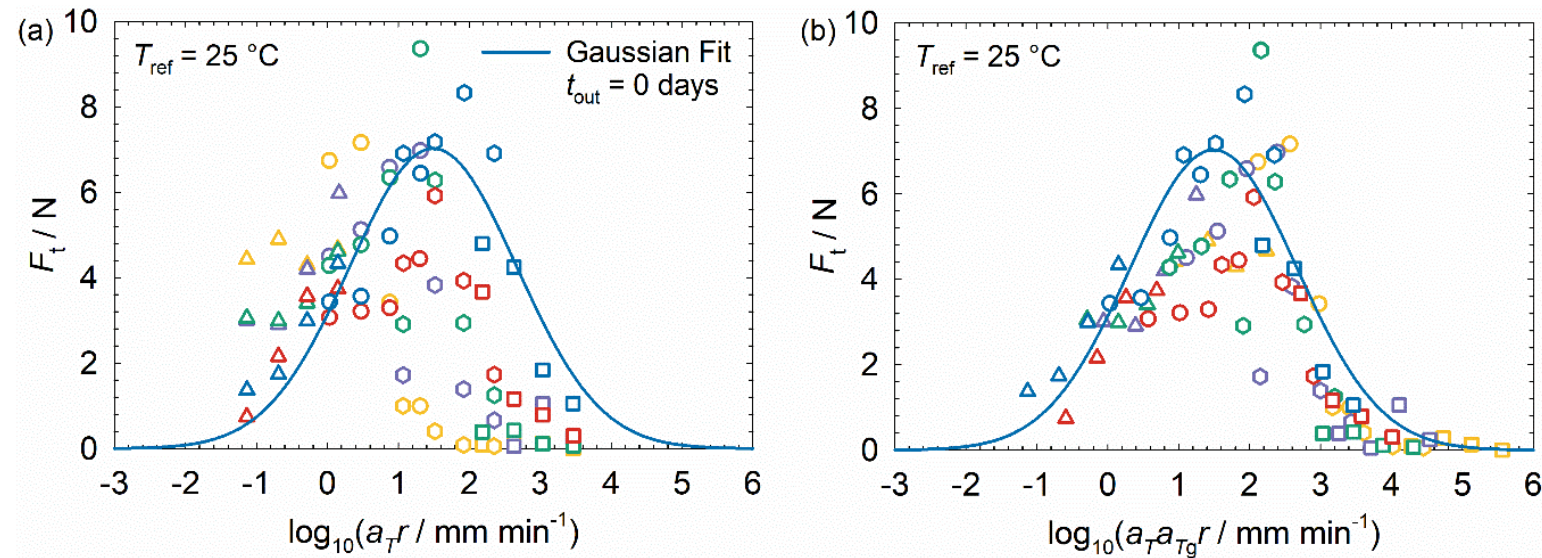

Fig. 11. Tack data at different out-times, $t_{\text {out, }}$ acquired at different temperatures, $T$, and feed rates, $r$. (a) tack data shifted to a reference temperature $T_{\text {ref }}=25^{\circ} \mathrm{C}$, illustrating the effect of out-time; (b) tack data shifted to $T_{\text {ref }}=25^{\circ} \mathrm{C}$ and additionally shifted from the respective $T_{\mathrm{g}}$ values to the 0 day $T_{\mathrm{g}}$, illustrating that once the change in $T_{\mathrm{g}}$ caused by the out-time is accounted for, tack master curves are very similar. The lines represent Gaussian curves fitted to $t_{\text {out }}=0$ day according to Eq. (8). 


\subsection{Tack process map}

Having demonstrated that changes in temperature and $T_{\mathrm{g}}$ bring about equivalent rate-dependent changes in tack according to the Arrhenius relationship given by Eq. (1), the Gaussian equation (Eq.(8)) can be modified to give an expression linking the tack force to deposition rate, $r$, deposition temperature, $T$, and resin $T_{g}$ :

$$
F_{\mathrm{t}}\left(T_{\text {ref }}, a_{T} a_{T_{\mathrm{g}}} r\right)=F_{\mathrm{t}, \max } \exp \left(-\left(\frac{\log _{10}\left(a_{T} a_{T_{\mathrm{g}}} r\right)-\log _{10}\left(r_{\text {max }, T_{\text {ref }}}\right)}{w}\right)^{2}\right)
$$

In order to populate Eq. (9), a baseline tack master curve fit is obtained using 0 day tack data. Eq. (9) can then be used to account for changes in tack associated with out-time by replacing the $T_{\mathrm{g}}$ term in $a_{T_{\mathrm{g}}}$ with the room-temperature cure model and DiBenedetto $T_{\mathrm{g}}$ model discussed in Sections 4.2 and 4.3.

Fig. 12 shows combinations of deposition temperature and deposition rate needed to obtain peak tack at various out-times. These curves are derived from tack data obtained at an out-time of 0 day and shifted to $T_{\text {ref }}=25^{\circ} \mathrm{C}$ as listed in Table 6 . For any out-time, the resin $T_{\mathrm{g}}$ can be estimated employing either the full model or a simpler linear regression, as described in Section 4.3. The shift factors $a_{T}$ and $a_{T g}$ are as defined in Eqs. (1) and (2). From Eq. (7), it can be observed that the rate at peak tack at deposition temperature $T_{\mathrm{d}}$, $r_{\text {max }, T_{\mathrm{d}}}$, can be related to the rate at peak tack at $T_{\text {ref }}, r_{\text {max }, T_{\text {ref }}}$ by employing a shift factor.

Therefore, the deposition temperature $T_{\mathrm{d}}$ (in Kelvin) required to achieve peak tack for a specific out-time with a corresponding $T_{\mathrm{g}}$ follows

$$
\frac{1}{T_{\mathrm{d}}}=\frac{1}{T_{\text {ref }}}+\frac{R}{E} \log _{10}\left(\frac{r_{\mathrm{max}, T_{\mathrm{ref}}}}{a_{T_{\mathrm{g}}} r_{\mathrm{max}, T_{\mathrm{d}}}}\right)
$$


The deposition temperature curves in Fig. 12 reveal that higher temperatures are required in order to obtain peak tack with increasing prepreg out-times.

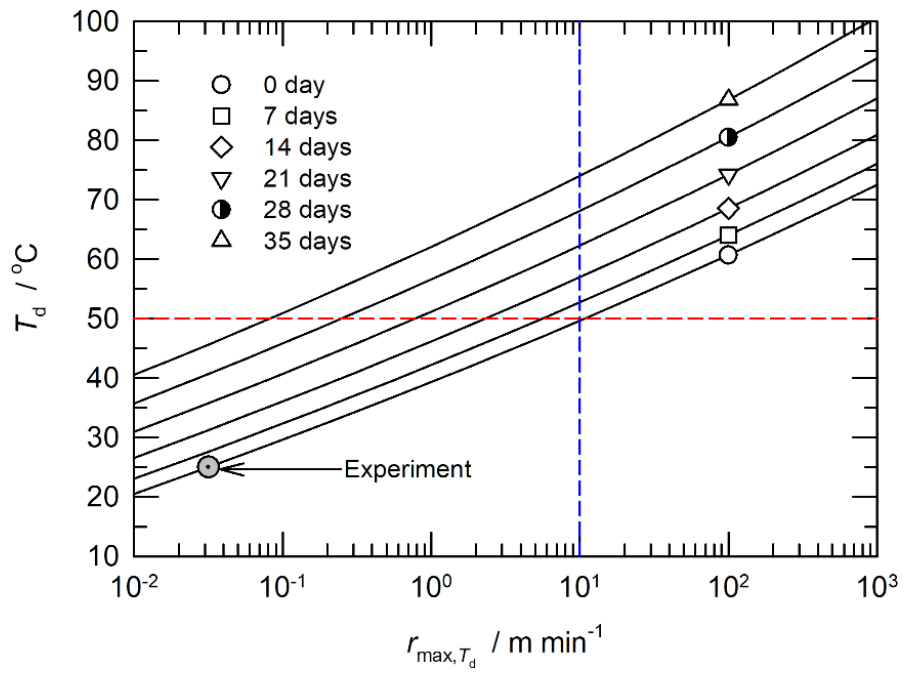

Fig. 12. Deposition temperature (Eq. (10)) as a function of deposition rate required to achieve peak tack for various prepreg out-times. Resin $T_{\mathrm{g}}$ for different out-times were determined using the room-temperature cure model (see Fig. 9). The circle dotted symbol shows an example of the shifted feed rate at maximum tack at $25^{\circ} \mathrm{C}$ that is derived from a Gaussian curve fitted to the single-stage peel measurements of prepreg without out-time. The dashed blue line represents a fixed deposition rate for the tack process map illustrated in Fig. 13(a) and the dashed red line represents a fixed deposition temperature for the tack process map presented in Fig. 13(b).

For practical application, combination of Eq. (9) with an ageing model can be implemented in the control software of the automated tape laying system, so that process parameters are adapted to suit out-times of specific prepreg tape rolls, and the need for manual intervention is removed. Alternatively, Eq. (8) can be used to generate process maps, for the benefit of manufacturers, which can provide insight for decision making regarding process design and intervention. For example, Fig. 13 shows the effect of deposition rate and deposition temperature on tack for 0 day of out-time. A value of $w=$ 1.66 is used as obtained from the 0 day out-time data. 
Fig. 14(a) shows the ratio of tack to peak tack that can be obtained at different outtimes by varying the deposition temperature at a fixed rate of $10 \mathrm{~m} \mathrm{~min}^{-1}$. On the other hand, if deposition temperature must remain fixed due to a matter of certification, Fig. 14(b) shows the ratio of tack to peak tack that can be obtained at different out-times by varying the deposition rate at a fixed temperature of $50{ }^{\circ} \mathrm{C}$. These process maps are represented by the dashed vertical and horizontal lines in Fig. 12.

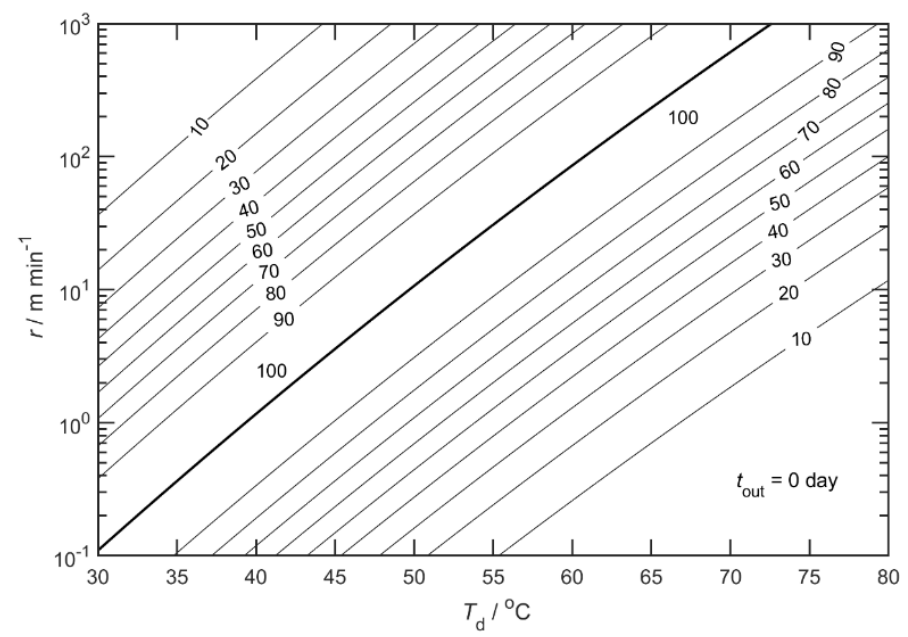

Fig. 13. Tack process map showing the effect of deposition rate and deposition temperature for prepreg without out-time, as shown in Fig. 12. 

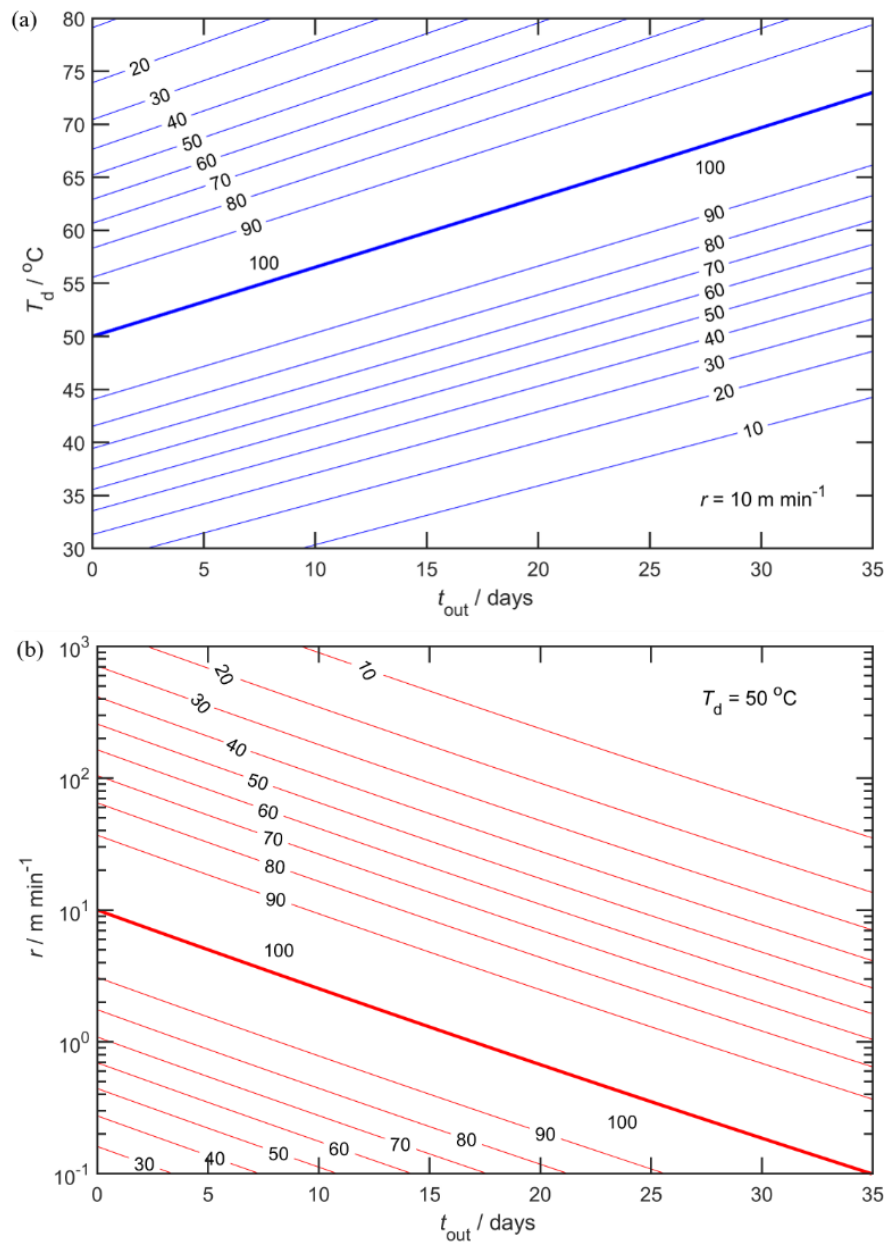

Fig. 14. Tack process maps showing the effect of out-time on (a) ideal deposition temperature for a fixed deposition rate of $10 \mathrm{~m} \mathrm{~min}^{-1}$, and (b) on deposition rate for a fixed deposition temperature of 50 ${ }^{\circ} \mathrm{C}$. Double $100 \%$ tack contours are a result of a $0.5 \%$ rounding tolerance imposed.

\section{Conclusions}

A single-stage peel method was used to determine the relationship between deposition temperature, deposition rate, and tack for a standard aerospace carbon/epoxy prepreg subjected to room-temperature out-time. In contrast to previous studies in which the WLF equation was used to capture the dependence of shift factors on temperature, the rheometry performed on prepreg specimens yielded a behaviour which was easily captured 
using a simpler Arrhenius equation. GPC results demonstrated that in this case, out-time had no significant effect on the molar mass distribution, and hence on the change in the length of resin polymer chains. Instead, changes in resin $T_{\mathrm{g}}$ were observed using DSC, which are thought to cause shifts in maximum tack to lower peel/deposition rates. Finally, a Gaussian curve describing the dependence of tack on peel/deposition rate at a given temperature was combined with Arrhenius equations used to account for differences in temperature and out-time by adjusting rates accordingly. Here, room-temperature cure and $T_{\mathrm{g}}$ models were implemented. The resulting tack master curves allow process maps to be generated, which provide insight for decision making and intervention in prepreg lay-up processes. The time-temperature dependence of the resin viscoelastic behaviour can potentially be implemented in the control software of an automated lay-up system to rapidly adapt process parameters to suit out-times of specific prepreg tape rolls. Such tailored processing control, particularly for preform manufacture of large structural components that takes several days to complete, is anticipated to improve resource utilisation, minimise lay-up defects and reduce the need for manual intervention to establish lay-up conditions.

\section{Acknowledgements}

The authors are grateful for financial support from McGill University and the Research Center for Higher Performance Polymer and Composites Systems (CREPEC). Bell Helicopter Canada Textron and Bombardier Aerospace are recognized for their material donations in the form of 8HS and PW prepreg sheets. Dr. Amanda Pearce is recognized for performing the GPC measurements referenced in the text. Nathan Hostettler 
from EPFL is recognized for the preparation of prepreg specimens prior to tack testing and for his input regarding the tack testing matrix. Finally, Sanesh Iyer is recognized for his input regarding the conceptualization of the tack process maps.

\section{Appendix}

Table A.1. Tack force, $F_{\mathrm{t}}$, determined at different test temperatures, $T$, and feed rates, $r$, for specimens with $t_{\text {out }}=0$ days; only average values are given; the specimen width was $75 \mathrm{~mm}$, the compaction force $100 \mathrm{~N}$.

\begin{tabular}{|c|c|c|c|c|}
\hline \multirow{2}{*}{$T /{ }^{\circ} \mathrm{C}$} & \multicolumn{4}{|c|}{$F_{\mathrm{t}} / \mathrm{N}$} \\
\hline & $r=25 \mathrm{~mm} \mathrm{~min}^{-1}$ & $r=70 \mathrm{~mm} \mathrm{~min}^{-1}$ & $r=180 \mathrm{~mm} \mathrm{~min}^{-1}$ & $r=500 \mathrm{~mm} \mathrm{~min}^{-1}$ \\
\hline 18 & 4.80 & 4.25 & 1.84 & 1.05 \\
\hline 28 & 6.91 & 7.18 & 8.33 & 6.91 \\
\hline 38 & 3.43 & 3.56 & 4.97 & 6.44 \\
\hline 50 & 1.37 & 1.74 & 2.99 & 4.34 \\
\hline
\end{tabular}

Table A.2. Tack force, $F_{\mathrm{t}}$, determined at different test temperatures, $T$, and feed rates, $r$, for specimens with $t_{\text {out }}=7$ days; only average values are given; the specimen width was $75 \mathrm{~mm}$, the compaction force $100 \mathrm{~N}$.

\begin{tabular}{|c|c|c|c|c|}
\hline \multirow{2}{*}{$T /{ }^{\circ} \mathrm{C}$} & \multicolumn{4}{|c|}{$F_{\mathrm{t}} / \mathrm{N}$} \\
\hline & $r=25 \mathrm{~mm} \mathrm{~min}^{-1}$ & $r=70 \mathrm{~mm} \mathrm{~min}-1$ & $r=180 \mathrm{~mm} \mathrm{~min}^{-1}$ & $r=500 \mathrm{~mm} \mathrm{~min}^{-1}$ \\
\hline 18 & 3.67 & 1.16 & 0.79 & 0.30 \\
\hline 28 & 4.34 & 5.92 & 3.93 & 1.73 \\
\hline 38 & 3.07 & 3.21 & 3.29 & 4.44 \\
\hline 50 & 0.75 & 2.16 & 3.57 & 3.74 \\
\hline
\end{tabular}

Table A.3. Tack force, $F_{\mathrm{t}}$, determined at different test temperatures, $T$, and feed rates, $r$, for specimens with $t_{\text {out }}=14$ days; only average values are given; the specimen width was $75 \mathrm{~mm}$, the compaction force $100 \mathrm{~N}$.

\begin{tabular}{|c|c|c|c|c|}
\hline \multirow{2}{*}{$T /{ }^{\circ} \mathrm{C}$} & \multicolumn{4}{|c|}{$F_{\mathrm{t}} / \mathrm{N}$} \\
\hline & $r=25 \mathrm{~mm} \mathrm{~min}^{-1}$ & $r=70 \mathrm{~mm} \mathrm{~min}^{-1}$ & $r=180 \mathrm{~mm} \mathrm{~min}^{-1}$ & $r=500 \mathrm{~mm} \mathrm{~min}^{-1}$ \\
\hline 18 & 0.39 & 0.43 & 0.11 & 0.07 \\
\hline 28 & 2.91 & 6.28 & 2.94 & 1.25 \\
\hline 38 & 4.28 & 4.77 & 6.34 & 9.36 \\
\hline 50 & 3.06 & 2.99 & 3.41 & 4.62 \\
\hline
\end{tabular}


Table A.4. Tack force, $F_{\mathrm{t}}$, determined at different test temperatures, $T$, and feed rates, $r$, for specimens with $t_{\text {out }}=21$ days; only average values are given; the specimen width was $75 \mathrm{~mm}$, the compaction force $100 \mathrm{~N}$.

\begin{tabular}{ccccc}
\hline \multicolumn{5}{c}{$T /{ }^{\circ} \mathrm{C}$} \\
\hline 18 & $r=25 \mathrm{~mm} \mathrm{~min}^{-1}$ & $r=70 \mathrm{~mm} \mathrm{~min}^{-1}$ & $r=180 \mathrm{~mm} \mathrm{~min}^{-1}$ & $r=500 \mathrm{~mm} \mathrm{~min}^{-1}$ \\
28 & 0.39 & 0.06 & 1.05 & 0.25 \\
38 & 1.72 & 3.83 & 1.39 & 0.66 \\
50 & 4.50 & 5.12 & 6.58 & 6.97 \\
\hline
\end{tabular}

Table A.5 Tack force, $F_{\mathrm{t}}$, determined at different test temperatures, $T$, and feed rates, $r$, for specimens with $t_{\text {out }}=35$ days; only average values are given; the specimen width was $75 \mathrm{~mm}$, the compaction force $100 \mathrm{~N}$.

\begin{tabular}{|c|c|c|c|c|}
\hline \multirow{2}{*}{$T /{ }^{\circ} \mathrm{C}$} & \multicolumn{4}{|c|}{$F_{\mathrm{t}} / \mathrm{N}$} \\
\hline & $r=25 \mathrm{~mm} \mathrm{~min}^{-1}$ & $r=70 \mathrm{~mm} \mathrm{~min}^{-1}$ & $r=180 \mathrm{~mm} \mathrm{~min}^{-1}$ & $r=500 \mathrm{~mm} \mathrm{~min}^{-1}$ \\
\hline 18 & 0.10 & 0.29 & 0.13 & $\sim 0.00$ \\
\hline 28 & 1.00 & 0.41 & 0.09 & 0.06 \\
\hline 38 & 6.74 & 7.16 & 3.42 & 0.99 \\
\hline 50 & 4.43 & 4.90 & 4.30 & 4.67 \\
\hline
\end{tabular}

\section{References}

[1] D. H. J. A. Lukaszewicz, C. Ward, and K. D. Potter, "The engineering aspects of automated prepreg layup: History, present and future," Composites Part B: Engineering, vol. 43, no. 3, pp. 997-1009, 2012.

[2] G. Marsh, "Automating aerospace composites production with fibre placement," Reinforced Plastics, vol. 55, no. 3, pp. 32-37, 2011.

[3] K. Fayazbakhsh, M. A. Nik, D. Pasini, and L. J. C. S. Lessard, "Defect layer method to capture effect of gaps and overlaps in variable stiffness laminates made by automated fiber placement," Composite Structures, vol. 97, pp. 245-251, 2013.

[4] J. P. H. Belnoue, T. Mesogitis, O. J. Nixon-Pearson, J. Kratz, D. S. Ivanov, I. K. Partridge, K. D. Potter and S. R. Hallett., "Understanding and predicting defect formation in automated fibre placement pre-preg laminates," Composites Part A: Applied Science and Manufacturing, vol. 102, pp. 196-206, 2017.

[5] J. Cemenska, T. Rudberg, and M. Henscheid, "Automated In-Process Inspection System for AFP Machines," SAE International Journal of Aerospace. vol 8, no. 2, pp. 303-309, 2015. 
[6] N. Bakhshi and M. Hojjati, "Time-dependent wrinkle formation during tow steering in automated fiber placement," Composites Part B: Engineering, vol. 165, pp. 586-593, 2019.

[7] B. Bockl, C. Jetten, K. Heller, C. Ebel, and K. Drechsler, "Assessment of the tack of prepreg slit tapes during the Automated Fiber Placement process," ed. 29th SICOMP Conference on Manufacturing and Design of Composites, 2018.

[8] B. Denkena, C. Schmidt, K. Völtzer, and T. Hocke, "Thermographic online monitoring system for Automated Fiber Placement processes," Composites Part B: Engineering, vol. 97, pp. 239-243, 2016.

[9] K. Heller, B. Bockl, C. Ebel, and K. Drechsler, "Influence of Prepreg Aging and Tack on Lay-Up Effects/Defects in Thermosets Automated Fiber Placement," presented at the 18th European Conference on Composite Materials, Athens, Greece, 2018.

[10] O. Dubois, J. B. Le Cam, and A. Beakou, "Experimental Analysis of Prepreg Tack," Experimental Mechanics, vol. 50, no. 5, pp. 599-606, 2010.

[11] A. Gillanders, S. Kerr, and T. Martin, "Determination of prepreg tack," International Journal of Adhesion and Adhesives, vol. 1, no. 3, pp. 125-134, 1981.

[12] R. Banks, A.P. Mouritz, S. John, F. Coman, and R. Paton, "Development of a new structural prepreg: characterisation of handling, drape and tack properties," Composite structures, vol. 66, no. 1, pp. 169-174, 2004.

[13] C. A. Dahlquist, "An investigation into the nature of tack," (in eng), Adhesives Age, vol. 2, pp. 25-29, 1959.

[14] K. J. Ahn, L. Peterson, J. C. Seferis, D. Nowacki, and H. G. Zachmann, "Prepreg aging in relation to tack," Journal of Applied Polymer Science, vol. 45, no. 3, pp. 399-406, 1992.

[15] A. Endruweit, G. Y. H. Choong, S. Ghose, B. A. Johnson, D. R. Younkin, N. A. Warrior, and D. S. A. De Focatiis, "Characterisation of tack for uni-directional prepreg tape employing a continuous application-and-peel test method," Composites Part A: Applied Science and Manufacturing, vol. 114, pp. 295-306, 2018.

[16] D. Budelmann, H. Detampel, C. Schmidt, and D. Meiners, "Interaction of process parameters and material properties with regard to prepreg tack in automated lay-up and draping processes," Composites Part A: Applied Science and Manufacturing, vol. 117, pp. 308-316, 2019.

[17] R. J. Crossley, P. J. Schubel, and N. A. Warrior, "The experimental determination of prepreg tack and dynamic stiffness," Composites Part A: Applied Science and Manufacturing, vol. 43, no. 3, pp. 423-34, 2011.

[18] "CYCOM(R) 5276-1 Epoxy Resin System," ed: Cytec Engineered Materials, 2012.

[19] R. J. Crossley, P. J. Schubel, and D. S. A. De Focatiis, "Time-temperature equivalence in the tack and dynamic stiffness of polymer prepreg and its application to automated 
composites manufacturing," Composites Part A: Applied Science and Manufacturing, vol. 52, pp. 126-33, 2013.

[20] G. Y. H. Choong, D. S. A. De Focatiis, and D. G. Hassell, "Viscoelastic melt rheology and time-temperature superposition of polycarbonate-multi-walled carbon nanotube nanocomposites," Rheologica Acta, vol. 52, no. 8, pp. 801-814, 2013.

[21] L. E. Nielsen, "Cross-Linking-Effect on Physical Properties of Polymers," Journal of Macromolecular Science, Part C, vol. 3, no. 1, pp. 69-103, 1969.

[22] J. P. Pascault and R. J. J. Williams, "Glass transition temperature versus conversion relationships for thermosetting polymers," Journal of Polymer Science Part B: Polymer Physics, vol. 28, no. 1, pp. 85-95, 1990.

[23] H. E. Adabbo and R. J. J. Williams, "The evolution of thermosetting polymers in a conversion-temperature phase diagram," Journal of Applied Polymer Science, vol. 27, no. 4, pp. 1327-1334, 1982.

[24] J. B. Enns and J. K. Gillham, "Time-temperature-transformation (TTT) cure diagram: Modeling the cure behavior of thermosets," Journal of Applied Polymer Science, vol. 28, no. 8, pp. 2567-2591, 1983.

[25] D. Dykeman, "Minimizing uncertainty in cure modeling for composites manufacturing," Ph.D., Materials Engineering, University of British Columbia, 2008.

[26] M. L. Williams, R. F. Landel, and J. D. Ferry, "The temperature dependence of relaxation mechanisms in amorphous polymers and other glass-forming liquids," J. Am. Chem. Soc., vol. 77, no. 14, pp. 3701-3707, 1955.

[27] C. Derail, A. Allal, G. Marin, and P. Tordjeman, "Relationship between Viscoelastic and Peeling Properties of Model Adhesives. Part 1. Cohesive Fracture," The Journal of Adhesion, vol. 61, no. 1-4, pp. 123-157, 1997. 